\title{
Mate-Guarding as a Male Reproductive Tactic in Propithecus verreauxi
}

\author{
V. Mass • M. Heistermann • P. M. Kappeler
}

Received: 23 April 2008 / Accepted: 19 October 2008 /

Published online: 11 March 2009

(C) The Author(s) 2009. This article is published with open access at Springerlink.com

\begin{abstract}
Sexual selection theory predicts that in group-living mammals, male reproductive tactics can lead to high reproductive skew in favor of dominant individuals. In sifakas (Propithecus verreauxi), a group-living primate with extremely seasonal reproduction, male reproductive success is highly skewed because dominant males sire almost all offspring despite a tendency toward an even adult group sex ratio. To understand the underlying behavioral mechanism resulting in this rank-related reproductive skew in male sifakas, we studied mate-guarding as a potential reproductive tactic. Behavioral observations of dominant males and adult females in combination with hormonal determination of timing of female receptivity in 9 groups at Kirindy Forest revealed that dominant males spent more time in proximity to females when they were receptive and were responsible for the maintenance of this proximity. Results also indicated that monopolization of receptive females was facilitated by both estrous asynchrony within groups and by the ability of dominant males to obtain olfactory cues as to the timing of female receptivity. Although dominant males engaging in mate-guarding are expected to experience various costs, there was no evidence for decreased foraging behavior and only a trend toward increased aggression between dominant and subordinate nonnatal males within groups. Our results are in accordance with the hypothesis that dominant males use mate-guarding to monopolize receptive females and that it one proximate mechanism that contributes to the high reproductive skew observed within the population of male sifakas at Kirindy.
\end{abstract}

\footnotetext{
V. Mass $(\bowtie) \cdot$ P. M. Kappeler

Department of Behavioral Ecology and Sociobiology, German Primate Center, Göttingen 37077 , Germany

e-mail: vmass@gwdg.de

V. Mass $\cdot$ P. M. Kappeler

Department of Sociobiology and Anthropology, University of Göttingen, Göttingen 37073, Germany

M. Heistermann

Department of Reproductive Biology, Germany Primate Center, Göttingen 37077, Germany
} 
Keywords mate-guarding - male reproductive tactics $\cdot$ Propithecus verreauxi . reproductive skew

\section{Introduction}

The mating system of a given species is shaped by the reproductive strategies of males and females (Clutton-Brock 1989), which in turn reflect their respective potential rates of reproduction (Clutton-Brock and Vincent 1991). By mating with many females, males can typically increase the number of offspring that they produce. Thus, males are limited in their reproductive success by their access to and monopolization of receptive females (Bateman 1948; Trivers 1972).

An important factor influencing male monopolization ability is the spatial and temporal distribution of fertile females (Emlen and Oring 1977; Ims 1988). According to socioecological theory, where females are clumped in space, males will try to monopolize access to the group of females while at the same time trying to exclude rival males from group membership. Similarly, if the temporal distribution of receptive females is even, a male will try to monopolize each female as they become receptive. As both female group size and/or estrous synchrony increases, a male's ability to monopolize the group decreases. Thus, one of the primary determinants of whether species form single-male or multi-male groups is the number and temporal distribution of resident females (Altmann 1990; CluttonBrock 1989; Emlen and Oring 1977; Kappeler 1999; Mitani et al. 1996a; Nunn 1999; cf. Kutsukake and Nunn 2006).

Where groups of females can potentially be monopolized by 1 male, contest competition between males is predicted (Clutton-Brock et al. 1977). This form of competition for access to mates can lead to the evolution of traits that improve or advertise fighting ability, such as large size and weaponry, and can result in sexual dimorphism (Plavcan 1999). Sexual dimorphism is most marked in strongly polygynous species because only a small proportion of the males in the population reproduce, and thus intense competition between males for access to receptive females is expected (Andersson 1994;Clutton-Brock et al. 1977; Mitani et al. 1996b; Plavcan 2001). This pattern is supported in male cercopithecoids (Plavcan and van Schaik 1997) but not in lemurs (Kappeler, 1990, 1991), even though male intrasexual competition for mates is intense.

Individual males can also increase their relative reproductive success by excluding rivals from mating (Andersson 1994; Plavcan 2001) via more indirect mechanisms of reproductive competition, such as physiological suppression or mateguarding, or both. Huck et al. (2004) defined mate-guarding as "preventing a receptive female from copulating with other males by maintaining close proximity, and it implies that the behavior is instigated by the male" (p. 40). Although it is not the prevailing male reproductive tactic in primates (Alberts et al. 1996), mateguarding occurs in a number of species, including moustached tamarins (Huck et al. 2004), long-tailed macaques (Engelhardt et al. 2006), and chimpanzees (Tutin 1979). Researchers have reported temporary mate-guarding in gray mouse lemurs (Eberle and Kappeler 2004) and pre- and post-copulatory mate-guarding in ring-tailed lemurs (Parga 2003; Sauther 1991). 
Although mate-guarding may increase a male's ability to monopolize access to a receptive female, the behavior may also incur costs. Aside from the increased risk of injury due to incursions with competing males, mate-guarding can lead to both an increase in energy expended and a decrease in energy consumed (restraints on foraging duration and foraging bout length) because mate-guarding requires active monitoring and following of a partner's movements (Alberts et al. 1996; Bercovitch 1983). In addition, mate-guarding may also carry physiological costs, such as increased glucocorticoid output as suggested from a study on sifakas (Propithecus verreauxi; Fichtel et al. 2007). Thus, males are expected to engage in this costly behavior only when a female is most likely to be fertile and receptive, and therefore, the ability to ascertain accurately when a female is in this reproductive stage in crucial (Alberts et al. 1996).

There are several cues that may serve as indicators of female reproductive status, including pheromones (Michael and Keverne 1968), sexual swellings (Brauch et al. 2007; Setchell and Wickings 2004), copulation calls (Semple 1998; van Schaik et al. 2004), and female sexual behavior (Aujard et al. 1998; Engelhardt et al. 2005; Zehr et al. 2000). Olfactory cues may be relatively more important in lemur species because they have often retained olfactory complexity, and the exchange of chemical signals plays an important role in communication (Schilling 1979). Thus, pheromones from urine, anogenital glands, and vaginal discharge may be a chemical signal communicating information about female reproductive status to both intragroup males and to extragroup males (Harrington 1974).

We studied male reproductive strategies in Verreaux's sifakas (Propithecus verreauxi) in an attempt to illuminate the proximate mechanism underlying male reproductive skew. Sifakas are arboreal lemurs that live in multi-male multi-female groups comprising 2-13 individuals (Richard et al. 1993) with variable adult sex ratios (Richard 1985). Female dominance and female philopatry are the norm, although females have occasionally been observed to disperse (Jolly 1966; Kubzdela 1997; Richard 1987; Richard et al. 1993, 2002). Females become receptive once per year (Brockman 1994; Brockman and Whitten 1996) for a period of $\leq 96 \mathrm{~h}$ (Brockman 1999) during a short mating season from January until March. Although the number of reproducing females within a group is small (1-3 individuals; Kubzdela 1997; Lewis 2005; Richard et al. 2002), dominant males do not exclude rival males from group membership, resulting in a tendency toward an even adult sex ratio. Despite the presence of multiple males within groups, according to genetic paternity analysis, reproduction in the Kirindy Forest population is highly skewed in favor of dominant individuals with dominant males siring almost all offspring (91\% of 33 infants; Kappeler and Schäffler 2008). In contrast, paternity analysis results for a population of Propithecus verreauxi at Beza Mahafaly revealed that extragroup fertilizations occur more frequently (Lawler 2007). Thus, although dominant males at Kirindy do not exclude rivals from group membership, they are somehow able to exclude both within and extragroup males from reproduction.

Although Brockman (1999) and Lewis and van Schaik (2007) described mateguarding in sifakas, here we attempt to quantify it for the first time. To determine whether dominant males use mate-guarding as a proximate mechanism to exclude rival males from reproduction, we tested the predictions that 1 ) females are receptive asynchronously within groups; 2) males increase their olfactory behavior when 
females are receptive; 3 ) dyads consisting of a female and the dominant male spend more time in proximity during the receptive period than in the mating season but there is no change in proximity between natal or non-natal subordinate males and females; 4) dominant males are responsible for both the initiation and maintenance of proximity with females; 5) in relation to the costs associated with mate-guarding, an increase in dominant male aggression rate toward rival males within the group occurs but not toward natal males, and a decrease in the total time dominant males spent feeding and their feeding bout lengths while females are receptive; and 6) if both males and females can enhance their mating opportunities through increased contact with neighboring groups, an increase in intergroup encounter rate when females are receptive occurs.

\section{Materials and Methods}

\section{Study Site and Population}

This study is part of an ongoing long-term study in Kirindy Forest, a dry deciduous forest in central western Madagascar, $60 \mathrm{~km}$ north of Morondava (Sorg et al. 2003). The site is operated by the Centre National de Formation, d'Etudes et de Recherche en Environnement et Foresterie (CNFEREF) Morondava. The German Primate Center has established a field station with 3 study areas within the forestry concession, where ongoing research has been conducted since 1993. We studied 9 groups of well habituated sifakas living in one of these study areas. All individuals in the study population are marked with either unique nylon collars and pendants or radio collars (Kappeler and Schäffler 2008). Group size and composition varied across the 9 study groups over the 2 sampling periods (Table I). We defined adulthood for males as $3 \mathrm{yr}$ (Kraus et al. 1999) because they have been observed to mate successfully at this age (Richard et al. 1991, 2002; Rümenap 1997). We included only females that had previously reproduced. We determined natal and nonnatal status genetically (Kappeler and Schäffler 2008).

\section{General Data Collection}

We performed observations during 2 sampling periods (January-March 2006 and $2007)$ encompassing 2 mating seasons. We observed dominant adult males $(n=10)$ and adult females $(n=12)$. Although there were 9 study groups, the number of dominant males observed was 10 because the dominant male in 1 group was replaced by another male at the start of the 2007 mating season. We identified the group's dominant male based on the outcome of decided agonistic interactions (Pereira and Kappeler, 1997). We observed 8 focal individuals from 4 different groups per day between 0600 and $1800 \mathrm{~h}$ with the help of a trained assistant (interobserver reliability: $r_{\mathrm{s}}=0.91$ ). Each focal animal observation session lasted either $2 \mathrm{~h}$ (January and February) or $1.5 \mathrm{~h}$ (March). In total, each observer spent either 3 or $4 \mathrm{~h}$ with 2 groups per day resulting in a total of 547.5 observation hours over the 2 sampling periods. Although observations were equally distributed over all focal individuals and observation hours, the number of observation hours per group 
Table I Composition of study groups over 2 sampling periods (excluding juvenile individuals) and observation hours

\begin{tabular}{lllll}
\hline Group & AF & AM & ANM & OH \\
\hline A (A1) & $1(1)$ & $1(2)$ & $0(1)$ & $59(30)^{\mathrm{a}}$ \\
B & 1 & 1 & $0-3$ & 155 \\
C & $1-2$ & 1 & $0-1$ & 102 \\
E & 1 & 1 & $1-2$ & 100 \\
F & $1-2$ & 1 & 3 & $38^{\mathrm{a}}$ \\
G & 2 & $1-3$ & 0 & 107 \\
H & 1 & $1-2$ & 0 & 107.5 \\
J & 1 & 2 & 0 & 101.5 \\
K & 2 & 1 & 0 & 164 \\
\hline
\end{tabular}

The group A dominant male-female dyad of 2006 was replaced at the start of the 2007 mating season due to the death of the adult female and the subsequent takeover of the group by a new male that became dominant. Range of numbers indicates changes in group composition due to disappearances, migration, or change of status from juvenile to adult. $\mathrm{AF}=$ adult females; $\mathrm{AM}=$ adult males (dominant and non-natal subordinate males); $\mathrm{ANM}=$ adult natal males; $\mathrm{OH}=$ observation hours per study group.

${ }^{a}$ Groups observed for 1 sampling period.

is not equal (Table I) owing to the exclusion of observations from this analysis if they fell outside the mating season, which we defined post hoc based on when females became receptive.

We collected behavioral data via continuous focal animal sampling (Altmann 1974). During each observation session, we continuously recorded the activity of the focal individual (foraging, resting, locomotion, and grooming). While the focal individual was engaged in an activity, we also recorded all instances of other individuals approaching (coming $\leq 1 \mathrm{~m}$ ) and departing (moving out of the $1 \mathrm{~m}$ radius) the focal individual. In addition, we noted when the focal individual approached or departed another individual. While the focal individual was engaged in a continuous activity, we recorded aggressive, submissive, olfactory, and reproductive events simultaneously. For aggressive and submissive behaviors (sensu Brockman 1994), we recorded the context, i.e., activity, the focal individual was engaged in and whether the interaction had a decided outcome, denoted by a clear submissive signal. If a series of aggressive and submissive events between the same dyad took place with no pause of $>1$ min between events, the series was considered 1 event. We recorded male olfactory behavior including place-sniffing (male sniffs the substrate where a female was resting $\leq 5 \mathrm{~min}$ after the female left), overmarking a female scent-mark (sensu Lewis 2005), anogenital sniffing (male approaches female from behind, sniffs her anogenital region, and scent marks in her urine), and general scent-marking (sensu Lewis 2005). We also noted reproductive behavior (sensu Brockman 1999). Finally, we sampled (sensu Lewis 2005) intergroup encounters ad libitum. We recorded the participants' location and whether the encounter was peaceful or agonistic. We conducted instantaneous focal point samples at 15-min intervals simultaneously during each focal animal observation and in addition by 2 field assistants who rotated through all focal females, excluding continuously 
observed focal animals, once per day to establish the distance of the focal individual to other group members yielding a total of 2763 scans.

\section{Fecal Sample Collection and Analysis}

To estimate day of ovulation, we collected fecal samples from the 12 focal females during both sampling periods. Frequencies of sample collection varied according to season from once per week during the pre- and post-mating season (December and March, respectively) to every second day during the mating season (January/ February), yielding a total of 637 samples (19-30 samples per female per sampling period). We collected a standardized amount of feces (9 pellets) immediately after defecation and stored them in $10 \mathrm{ml}$ of $70 \%$ ethanol until hormone analysis (Kraus et al. 1999). We collected all samples in the morning between 0600 and $1130 \mathrm{~h}$ to control for potential diurnal variation in hormone excretion. In groups with $>1$ adult female, we collected samples from all females within the group on the same day.

\section{Fecal Extraction and Hormone Analysis}

Before hormone measurement, we homogenized samples in their original ethanolic solvent (Kraus et al. 1999) and subsequently extracted them twice as described by Ziegler et al. (2000) with the modification that we vortex-mixed samples twice for $10 \mathrm{~min}$ on a multitube vortexer instead of shaking them overnight on a horizontal shaker. Efficiency of the extraction procedure, determined by monitoring the recovery of $\left[{ }^{3} \mathrm{H}\right]$ progesterone added to a subset of samples before homogenization, was $74.1 \pm 4.5 \%$ (mean $\pm \mathrm{SD}, n=12$ ). After extraction, we dried the remaining fecal pellets in a vacuum oven and determined the dry weight of the samples. All hormone concentrations are expressed as mass per gram of dry weight.

We measured fecal extracts for levels of immunoreactive progesterone (iP4), which has been shown to provide reliable information on female ovarian activity in sifakas (Brockman and Whitten 1996). We performed enzyme immunoassay according to the procedure described previously by Heistermann et al. (1993). The assay used an antibody raised in sheep against progesterone-11 $\alpha$-hemisuccinatebovine serum albumin (BSA) and progesterone-3-horseraddish peroxidase (POD) as label. We assayed 50- $\mu 1$ aliquots of fecal extracts (diluted 1:20-1:100 in assay buffer) along with $50 \mu \mathrm{l}$ of standard reference solutions (range $2.5-160 \mathrm{pg}$ ). Sensitivity of the assay at $90 \%$ binding was $3 \mathrm{pg}$. Serial dilutions of fecal extracts from different females gave displacement curves parallel to the progesterone standard curve. Intraand interassay coefficients of variation, calculated from replicated measurements of high- and low-value quality controls, were 7.2\% $(n=16)$ and $12.5 \%(n=21$; high $)$ and $8.1 \%(n=16)$ and $14.3 \%(n=21$; low $)$, respectively.

We used the fecal progesterone profiles to determine the presumed day of ovulation and thereby to define the period of estrus in each female. In this respect, we interpreted the significant rise in fecal iP4 levels above a threshold of the mean plus 2 standard deviations of 4-5 preceding baseline (follicular phase) values as indicating that ovulation occurred. Researchers have widely used this approach to estimate the day of ovulation in various primate species, e.g., capuchins (Carosi et al. 1999), hanuman langurs (Heistermann et al. 2001), and long-tailed macaques 
(Engelhardt et al. 2004). We assessed the presumed day of ovulation as the day of the defined fecal iP4 increase corrected for a time lag of $2 \mathrm{~d}$ to account for steroid passage time to excretion into feces (Brockman and Whitten 1996; Shideler et al. 1993). Because we collected samples every other day, estimated timing of ovulation may include an error of $1-2 \mathrm{~d}$.

\section{Data Analysis}

To determine whether there was a change in male behavior while females were receptive, we divided the sampling period into 2 periods: mating season (MS) and receptive period (RP). MS was the time from the onset of the first female's period of receptivity in the population to the termination of the last female's period of receptivity. We calculated the RP for each female and defined it as the presumed day of ovulation $\pm 7 \mathrm{~d}$. This operationally defined period of female receptivity takes into account possible visual changes in female morphology that could signal the onset of receptivity (Richard 1974b, 1992; Sauther 1991) and also addresses the confines of observing several study groups simultaneously. The use of this extended RP instead of the biologically true period of female receptivity for behavioral analysis is expected to dilute results and thus underestimate the true frequencies of behavior. We did not additionally include data collected during the RP of each female in the MS. Because estrous behavior, defined as female willingness to mate (Brockman and Whitten 1996), is difficult to observe at Kirindy, we defined estrus hormonally as the presumed day of ovulation $\pm 2 \mathrm{~d}$, referred to as the fertile period (Fig. 1). This definition takes into account maximum estrus (96 h) (Brockman 1999) and gut transit time (Shideler et al. 1993; Wasser et al. 1988). We used the fertile period to test for estrous synchrony within groups and within the population. Estrous synchrony refers to the complete or partial temporal overlap of the fertile period of individual females, whereas asynchrony is the temporal non-overlap of estrus (Brockman and Whitten 1996).

To examine male olfactory behavior, we pooled all occurrences of place-sniffing, over-marking and anogenital sniffing (hereby referred to as sex-related olfactory

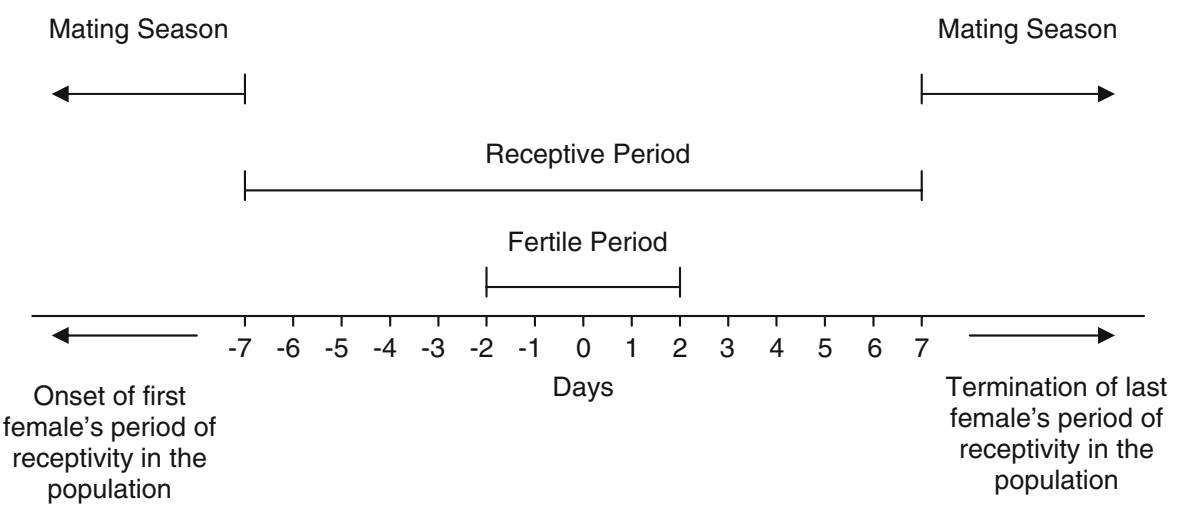

Fig. 1 Schematic representation of operational definitions used for analysis wherein 0 days indicates the presumed day of ovulation for each individual female within the study population. 
behaviors) for each male over both sampling periods to have a sufficient sample size for analysis. We compared individual male sex-related olfactory behavior rates per hour during the RP and the MS. We also calculated male scent marking rates per hour and tested for differences between the MS and RP. For 1 male, we included only data collected during the 2006 MS in the analyses because both females present in the group did not come into estrus during the 2007 MS.

We analyzed changes in proximity for dominant, non-natal subordinate and natal male-female dyads using the distance data collected during instantaneous focal point sampling. We divided data on each dyad into 2 distance categories: $0-5 \mathrm{~m}$ and $>5 \mathrm{~m}$. We added the total number of point samples in both the MS and divided the RP for each dyad into number of point samples dyads spent in close proximity (0$5 \mathrm{~m})$ and further apart $(>5 \mathrm{~m})$. We tested differences in the proportion of total point samples per season that male-female dyads spent in close proximity. We then tested for differences in close proximity during the RP among the 3 types of male-female dyads. Subordinate males included were adults, although 4 natal subordinate males were between 3-4 yr of age. Although some individuals contributed to $>1$ dyad, i.e., groups with 2 focal females, we considered dyads as the biologically meaningful and independent unit of analysis (de Vries 1998). We excluded 1 dyad from this analysis due to the extremely low number of point samples collected during the RP.

To determine the extent to which proximity was due to the movements of 1 member of the dyad rather than the other, we calculated the Hinde index (HI; Hinde and Atkinson 1970), using counts of approaches and departs for female-dominant male dyads. The index does not provide a reliable measure for small sample sizes (Hinde 1977), and thus we analyzed only dyads with $>16$ approaches and departs (Hill 1990). We regarded values between -0.1 and 0.1 as uninformative because these slight differences in responsibility may occur by chance (Hill 1987).

Finally, to ascertain which individual class (female or dominant male) was responsible for the initiation of bouts of proximity during the RP, we calculated an approach rate per hour total individual observation time for both females and dominant males and tested for differences between the 2 classes of individuals. We then compared dominant male approach rates in the MS and RP.

To test if males experience an increased risk of injury, a potential cost associated with mate-guarding behavior, we calculated aggression rates per hour for dominant males based on counts of aggressive acts toward non-natal subordinate males present in the group. We also calculated dominant male aggression rates toward group natal males for comparative purposes. We tested for differences in aggression rate between the MS and RP. We included only agonistic interactions with a decided outcome for analysis. In relation to foraging behavior, we calculated the percentage of total observation time a dominant male spent feeding in both the MS and the RP and tested for differences between the 2 periods. In addition, we calculated the average dominant male feeding bout duration length (minutes) as a direct measure of how long an individual fed without interruption. Owing to a constant need to monitor the movements of a female, a male may experience frequent interruptions while feeding, which may not be reflected in the overall time spent engaged in this activity but would result in a decrease in feeding bout duration (Alberts et al. 1996). We tested for differences in feeding bout length between the MS and the RP. 
Finally, we calculated the number of intergroup encounters for each group in the MS and the RP. We then divided the total for each period by the number of hours the group was observed in each period to obtain an intergroup encounter rate per period. We then tested for differences between the RP and the MS. In addition, we tested for differences in the proportion of encounters that were peaceful or agonistic in both the MS and RP.

We used nonparametric statistics to test for differences between seasons and individual dyads. We analyzed data via STATISTICA (StatSoft Inc., version 6.0, 2001) and set the significance level at $p<0.05$.
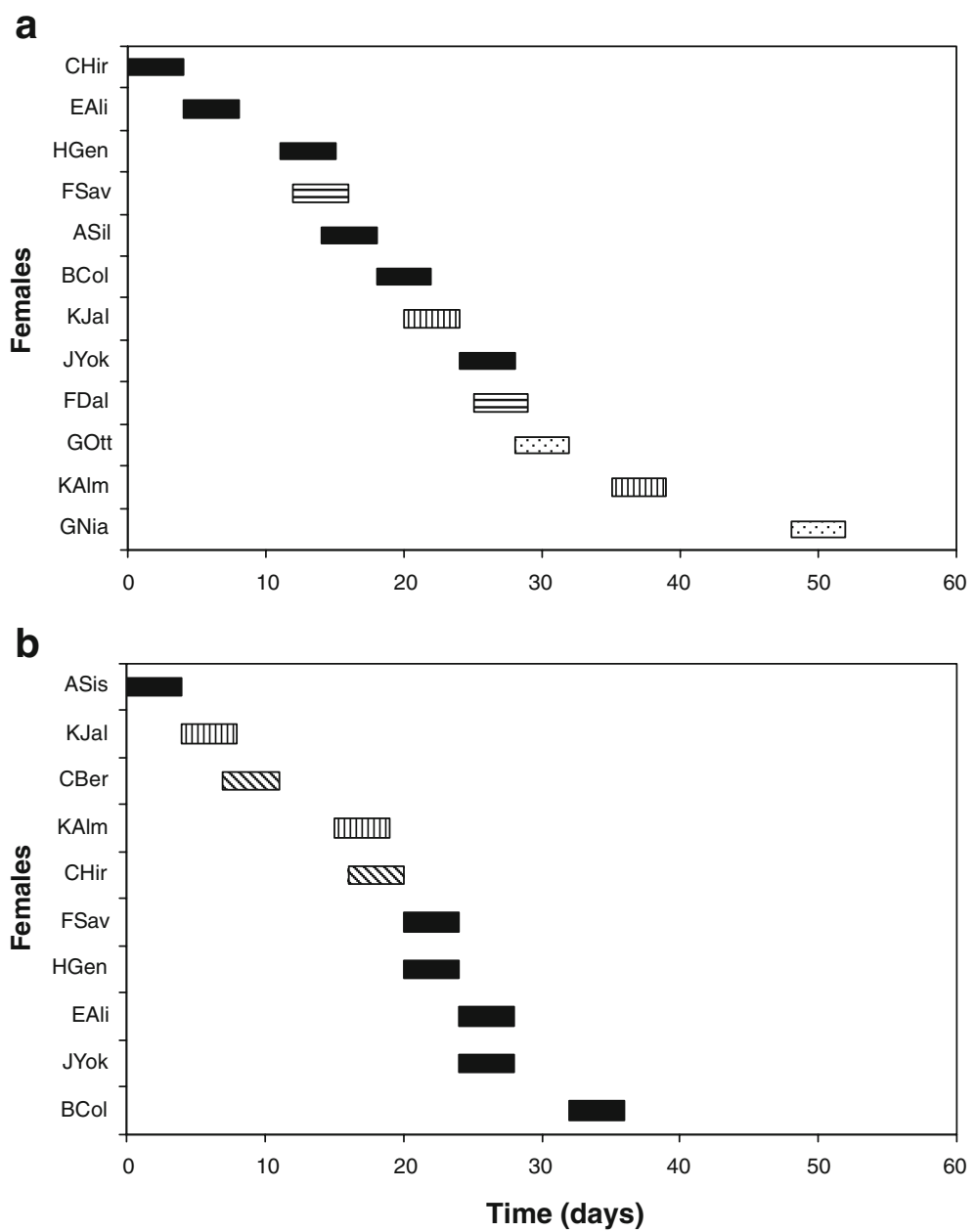

Fig. 2 Distribution of female fertile periods in the 2006 (A) and 2007 (B) mating seasons. The first letter of female identification represents the group of which the female is a member. Females in the same group share the same shading pattern. Females depicted in black are the only females present in their group (single female groups). The shorter duration of the 2007 mating season may be due to the fact that two females did not come into estrus while we collected fecal samples although 1 female may have become receptive after sampling had stopped as she had an infant late in the birth season. 


\section{Results}

\section{Female Estrous Synchrony}

We performed hormone analysis for 12 females in both sampling periods. All 12 females came into estrus in 2006 but only 10 out of 12 in 2007 . The duration of the MS was $52 \mathrm{~d}$ (2006) and $36 \mathrm{~d}$ (2007), respectively. Fertile periods were more evenly distributed in 2006 and more clumped in 2007 (Fig. 2). Females residing in the same group came into estrus asynchronously, i.e., no temporal overlap, with a mean $( \pm$ SD) of $13 \pm 2.5 \mathrm{~d}$ (2006) and $10 \pm 1.4 \mathrm{~d}$ (2007) between the fertile periods of each female within a group (Fig. 2). At the population level, most females $(n=22)$ were synchronous with 1 or 2 other females in the population ( $64 \%$ and $18 \%$, respectively) but only $5(28 \%)$ females were synchronous with females in neighboring groups, whereas $15(83 \%)$ females came into estrous synchronously with non-neighboring females.

\section{Olfactory Behavior}

We observed a total of 179 male sex-related olfactory behavior patterns over both sampling periods. Males increased their rate of sex-related olfactory behavior during the RP in comparison to the MS (Wilcoxon-test: $T=8, n=10, p=0.047$, median ${ }_{\mathrm{MS}}=$ 1.38 , range $=0.08-2.25$; median ${ }_{R P}=2.14$, range $=0.75-3.75$; Fig. 3 ). There was no difference in the median rate of general male scent marking behavior between the MS and the RP (Wilcoxon-test: $T=21, n=10, p=0.86$, median $_{\mathrm{MS}}=2.69$, range $=1-6$; median ${ }_{\mathrm{RP}}=2.31$, range $\left.=1-6.25\right)$.

\section{Female-Dominant Male Dyad Proximity}

Dominant males spent a higher proportion of total point samples in close proximity to females in the RP in comparison to the MS (Wilcoxon-test: $T=7, n=10, p=0.037$,

Fig. 3 Median rate per hour of male sex-related olfactory behavior in the mating season and the receptive period $(n=10)$. The rate is significantly higher in the receptive period ( $p=0.047)$.

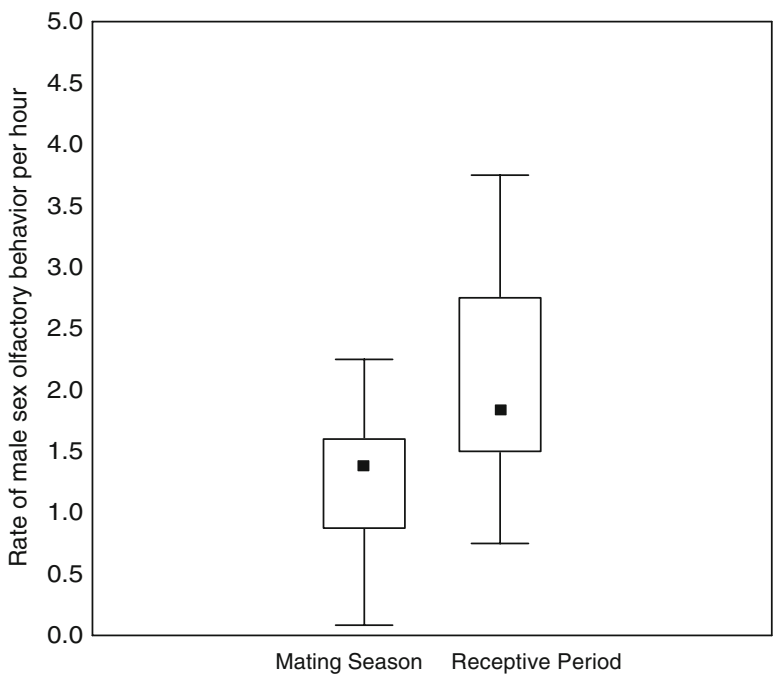


median $_{\mathrm{MS}}=0.52$, range $=0.34-0.76$; median $_{\mathrm{RP}}=0.61$, range $\left.=0.46-0.70\right)$ but there was no such difference for either female-non-natal subordinate male dyads (Wilcoxon-test: $T=6, n=7, p=0.18$, median ${ }_{\mathrm{MS}}=0.14$, range $=0.06-0.27$; median ${ }_{\mathrm{RP}}=0.17$, range $=0$ 0.43 ) or female-natal subordinate male dyads (Wilcoxon-test: $T=4, n=7, p=0.09$, median $_{\mathrm{MS}}=0.35$, range $=0.18-0.56$; median ${ }_{\mathrm{RP}}=0.18$, range $\left.=0.11-0.53\right)$. In the $\mathrm{RP}$, we found that female-dominant male dyads were in close proximity more often than both non-natal subordinate and natal male-female dyads (Kruskal-Wallis: $H=16.16$, $n=24, p=0.003$; post hoc MWU-test dominant vs. non-natal subordinate male-female dyads: $U_{10,7}=0, p=0.0006$; dominant vs. natal male-female dyads: $U_{10,7}=1.5, p=$ 0.001; non-natal vs. natal male-female dyads: $U_{7,7}=22.5, p=0.80$; Fig. 4).

Analysis of the Hinde index (HI) showed that bouts of proximity were maintained by the dominant male over both the MS $(\mathrm{HI}=0.15)$ and the $\mathrm{RP}(\mathrm{HI}=0.29)$. Dominant males were not more responsible for the maintenance of proximity in the RP in comparison to the MS (Wilcoxon-test: $T=27, n=12, p=0.35$ ). Finally, when analyzing approach rates per hour, we found that dominant males both initiated bouts of proximity more often than females did in the RP (MWU-test: $U_{12,12}=27.5$, $p=0.01$, median males $=1.41$, range $=0.31-5.17$; median females $=0.75$, range $=0.13-$ 1.25 ) and that males approached females at a higher rate in the RP vs. the rest of the MS (Wilcoxon-test: $T=9, n=12, p=0.019$, median $\mathrm{MS}=0.84$, range $=0.47-1.53$; median $_{\mathrm{RP}}=1.41$, range $\left.=0.31-5.17\right)$.

\section{Costs of Mate-Guarding}

We observed a total of 23 agonistic interactions for 5 dominant male-non-natal subordinate male dyads of which 21 were decided. All 9 interactions observed for 7 dominant male-natal male dyads were decided. Although we could not statistically compare aggression rates between the MS and the RP for dominant male-non-natal males dyads because of low sample size $(n=5)$, mean aggression rates were more than double during the RP (mean $=0.67 \pm 0.22$ aggression events/h, $n=13$ ) when compared to the MS (mean=0.30 \pm 0.29 aggression events $/ \mathrm{h}, n=8$; Fig. 5 ). In the RP, $85 \%$ of agonistic interactions took place in the context of resting while only $15 \%$

Fig. 4 Proportion of scans that dominant, non-natal subordinate and natal male-female dyads were in close proximity $(0-5 \mathrm{~m})$ in the receptive period. There is a highly significant difference between dominant male-female dyads $(n=10)$ and both non-natal subordinate $(n=7, p=0.0006)$ and natal $(n=7, p=0.001)$ malefemale dyads but no difference in close proximity between nonnatal subordinate and natal malefemale dyads $(p=0.8)$ in the receptive period.

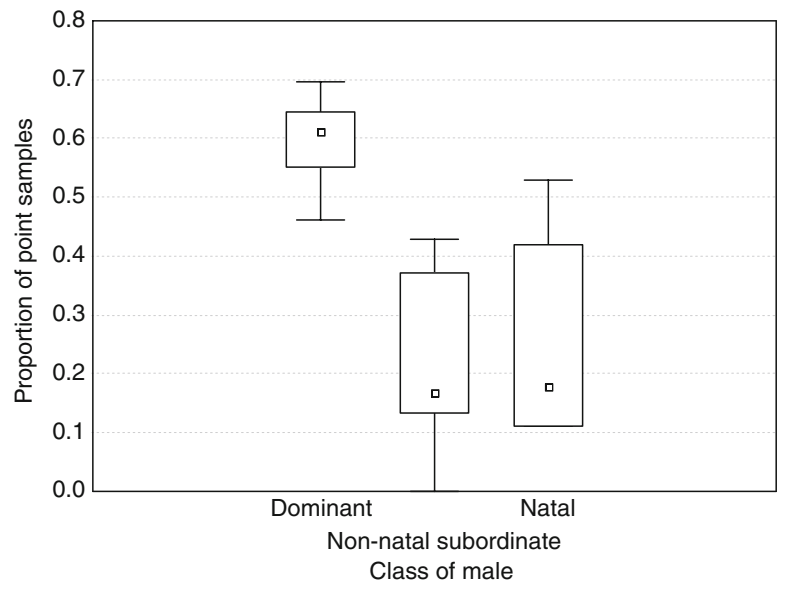


Fig. 5 Dominant malesubordinate non-natal male dyad aggression rates per hour during the mating season and the receptive period. We could not test data statistically owing to low sample size $(n=5)$.

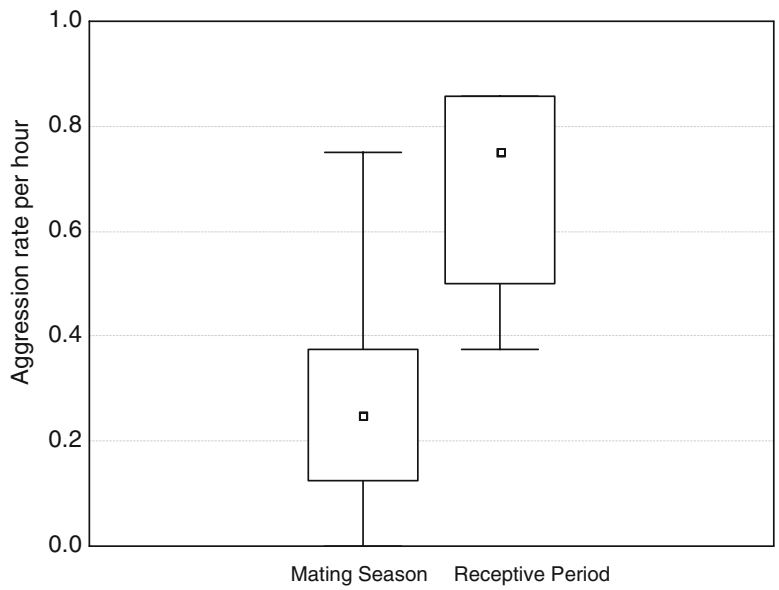

occurred in the context of feeding. Of the 21 interactions observed over both periods, $67 \%$ were displacements. The proportion of displacements increased to $85 \%$ (11 of 13 interactions) in the RP. The frequency of aggressive interactions by dominant males toward natal males was so low that we did not test for statistical differences between the MS (mean=0.04 \pm 0.08 aggressive events $/ \mathrm{h}, n=4)$ and the RP (mean= $0.06 \pm 0.09$ aggressive events/h, $n=5$ ).

The foraging behavior of dominant males did not differ between the MS and the $\mathrm{RP}$ in either time spent feeding (Wilcoxon-test: $T=18, n=10, p=0.33$, median ${ }_{\mathrm{MS}}=$ 0.45 , range $=0.36-0.59$; median ${ }_{\mathrm{RP}}=0.41$, range $=0.27-0.59$ ) or average feeding bout length (minutes; Wilcoxon-test: $T=9, n=10, p=0.4$, median $_{\mathrm{MS}}=4.5$, range $=3.0-7.5$; median ${ }_{\mathrm{RP}}=4.0$, range $\left.=3.0-5.5\right)$.

\section{Intergroup Encounter Rate}

We observed a total of 35 intergroup encounters over the MS and RP during both sampling periods. Although the rate of intergroup encounters during the RP was higher than in the MS, the difference is not significant (Wilcoxon test: $T=20, n=10$ groups, $p=0.44$, median ${ }_{\mathrm{MS}}=0.04$, range $=0.0-2.5$; median $\mathrm{RP}=0.09$, range $=0.0$ $0.19)$. Within both the MS and RP, agonistic encounters occurred more frequently than peaceful encounters (Chi-squared ${ }_{\mathrm{MS}}: \chi^{2}=8.5, \mathrm{df}=1, p=0.004$; Chi-squared ${ }_{\mathrm{RP}}$ : $\left.\chi^{2}=4.3, \mathrm{df}=1, p=0.04\right)$.

\section{Discussion}

Our results demonstrate a quantitative change in several measures of proximity in female-dominant male dyads between the MS and the RP, which suggest the use of mate-guarding as a reproductive tactic by dominant male sifakas. This conclusion is in concordance with previous descriptions of the behavior in sifakas of this and other populations (Brockman 1999; Lewis and van Schaik 2007). In comparison to both non-natal subordinate and natal male-female dyads, female-dominant male dyads 
spent more time in close proximity during the RP and these bouts of proximity were both primarily initiated and maintained by the dominant male. Although some of these measures may include behavior patterns not directly associated with mate-guarding, the changes in the different proximity measures between receptive and non-receptive periods suggest that dominant male sifakas used a form of mate-guarding.

The dominant male's ability to mate-guard may have been facilitated by female estrous asynchrony and the ability to pick up olfactory cues as to the timing of female receptivity. We predicted that males engaging in mate-guarding should face the costs associated with the behavior. Our results suggest that there is no change in dominant male foraging behavior when females are receptive, although this result could be due to our definition of RP and because feeding rates were not considered in our analysis. However, there may be an increase in aggression toward rival males within the group while a female is receptive, and thus a physiological cost could be incurred by both dominant and non-natal subordinate males because increased rates of aggression have been shown to be related to higher glucocorticoid levels, a hormonal measure of stress (Fichtel et al. 2007).

\section{Female Estrous Asynchrony}

When females come into estrus asynchronously, a decrease in the variance of male reproductive success in predicted (Altmann 1990; Emlen and Oring 1977; Kappeler 1999; Mitani et al. 1996a). Although a recent cross-species comparative study found no evidence for a link between male mating skew and female estrous synchrony in primates (Kutsukake and Nunn 2006), male reproductive skew, conversely, may be linked with female estrous asynchrony, as has been shown for several species including domestic cats (Say et al. 2001) and brown lemurs (Gachot-Neveu et al. 1999). Hormone analysis results show that female sifakas living in the same group came into estrus asynchronously. Under these circumstances, the dominant male can effectively monopolize both females, which may explain the extreme reproductive skew in favor of dominant males in the Kirindy population.

\section{Olfactory Cues to Female Receptive State}

Although general male scent marking remained constant, as Lewis (2005, 2006) found for the same population, there was an increase in male sex-related olfactory behavior during the RP. The findings are similar to those for ring-tailed lemurs (Palagi et al. 2004) and moustached tamarins (Huck et al. 2004), where male olfactory investigation of female scent marks increased in the mating season. Even though our finding suggests that males may be using olfactory cues as an indicator of female receptive state, caution is warranted. If the composition of female scent marks change, and thus the information that is communicated, males do not need to increase the frequency of olfactory behavior to obtain valuable information. Studies on closely related species have shown that the volatile components of female anogenital gland secretions vary between birth and mating season in Propithecus edwardsi (Hayes et al. 2006) and can reveal specifics regarding reproductive status in Propithecus verreauxi coquereli (Hayes et al. 2004). In addition, the possibility 
that males may also use other cues, such as morphological changes of the vulva (Richard 1974b, 1992; Sauther 1991), cannot be excluded.

Although the function of female scent marking in Propithecus spp. does not appear to be to attract mates (Lewis 2006; Pochron et al. 2005) and females actually decrease the frequency of marking behavior during estrus (Brockman, 1999), scent marks may nevertheless communicate information about reproductive status (Lewis 2006). Thus, although there are no data on either the composition or change in composition of female anogenital gland secretions in Propithecus verreauxi, males may be able to obtain some information regarding female reproductive state via olfactory cues.

If dominant males are able to ascertain the timing of female receptivity via olfactory cues, we can expect that the information conveyed in a female scent mark is public information accessible to all males. Moreover, females scent mark more in the periphery of their territories where scent marks have a higher probability of being investigated by extragroup males (Lewis 2005), making it possible for males to gain information on female receptive state without visual contact (Richard 1985). One possible tactic to limit rival male access to information on female reproductive state is for dominant males to overmark female scent marks (Lewis 2005). This male reproductive tactic is common in several species of vole (Ferkin et al. 2004), has been shown to occur in ring-tailed lemurs (Kappeler 1998), and is suggested for owl monkeys (Wolovich and Evans 2007). In sifaka, males overmark female scent marks more frequently in the mating season and during intergroup encounters (Lewis 2005). These findings support the use of overmarking as a male reproductive tactic in sifaka.

\section{Costs of Mate-Guarding Behavior}

If olfactory cues are accessible to all males, including both intragroup and extragroup males, we would expect an increase in the rate of male-male aggression when females are receptive as males would compete for access to receptive females. For example, in ring-tailed lemurs, male dominance hierarchies break down and intermale aggression increases in the mating season (Cavigelli and Pereira 2000; Gould and Ziegler 2007; Jolly 1966). Increases in male-male aggression rates also increase in species that have stable dominance hierarchies in the mating season, e.g., red-fronted brown lemurs (Ostner et al. 2002). Mate-guarding males thus face an increased risk of injury owing to incursions with rival males while trying to monopolize access to receptive females (Matsubara 2003). Although we could not test statistically changes in male-male aggression rates, the data suggest that there may be an increase in aggression towards non-natal subordinate males during the RP that is not associated with feeding competition. Even so, the overall rate of aggression in the Kirindy population is low (Lewis and van Schaik 2007), which suggests that males are not physically fighting for access to females.

Low aggression rates may reflect the fact that the number of groups in our study with $>1$ non-natal male is low ( 3 groups of 9) and that the groups were stable. Thus, although aggression does exist, its importance relative to acquiring and monopolizing mates may be minimized. Moreover, the fact that aggression generally takes the form of high speed arboreal chases lends support to the idea that selection in sifakas 
is not operating on physiological traits that increase body mass and weaponry, which lead to sexual dimorphism, but rather on traits that improve speed and agility (Lawler et al. 2005).

If olfactory cues are available to all males, we would also expect an increase in intergroup encounter rate during the RP, especially due to both the high proportion of female estrous asynchrony in neighboring groups and a high degree (36.5-63.7\%) of home range overlap (Benadi et al. 2008). One option for males to increase their reproductive success is to mate with extragroup females. For example, in banded mongooses, intergroup encounter rates increase when females are receptive as males may be actively seeking extragroup copulations in pursuit of paternity (Cant et al. 2002). Mating with extragroup males is also a beneficial strategy for females as a means to confuse paternity and thus decrease the risk of infanticide if the group is taken over by a new male (van Schaik and Janson 2000). Because Lewis et al. (2003) documented infanticide in the Kirindy population of sifakas, mating with extragroup males would also benefit females. Although this does occur in another population of Propithecus verreauxi (Lawler 2007), the genetic data reveled only 1 extragroup paternity within the Kirindy population (Kappeler and Schäffler 2008).

The stability of the intergroup encounter rate was thus surprising but there may be several explanations for this result. If dominant males are mate-guarding effectively, attempting to mate with extragroup females during intergroup encounters may not be worth the risk of potential injury. In addition, by leaving females in their resident group in search of extragroup females, dominant males may risk losing paternity. The tradeoff between staying and searching for more females may be such that the benefits of staying in the resident group outweigh the chance of reproductive success elsewhere. Alternatively, sneaky copulations with lone males (Lewis and van Schaik 2007) and during intergroup encounters (Brockman 1999) may indeed occur but do not result in fertilizations. Thus, although reproductive skew is high (Kappeler and Schäffler 2008), the mating skew may be more evenly distributed between males, especially because subordinate males have been observed to mate (Lewis 2004).

\section{Intraspecific Variation in Male Reproductive Success in Verrreaux's sifaka}

Although Richard (1974a) documented intraspecific variation in the social organization and ecology of Propithecus verreauxi, several of our findings may help to illuminate slight variations within the mating system. Male reproductive success differs between the population at Kirindy (Kappeler and Schäffler 2008), and the population studied at Beza Mahafaly Special Reserve in Southwest Madagascar (Lawler et al. 2003) as reproduction is more skewed at Kirindy. This discrepancy may be due to differences between populations in female reproductive strategies, i.e., female estrous asynchrony and female choice.

In a study conducted to document intragroup estrous asynchrony at Beza, results revealed that estrus was asynchronous within 1 group but synchronous within the other (Brockman and Whitten 1996). Although the sample size was small, the result may lend insight into the differences in reproductive skew. Although resident males at Beza also sire the majority of offspring, the percentages are lower, 35-83\% (Lawler, 2007; Lawler et al. 2003) than for the Kirindy population (91\%; Kappeler 
and Schäffler 2008). This difference may be due to the inability of males to monopolize all group females if females are receptive synchronously.

In addition, Lawler et al. (2003) found that a significant fraction of offspring were sired by nonresident males at Beza when the adult sex ratio was biased toward females. At Kirindy, genetic analysis revealed only 1 extragroup paternity (Kappeler and Schäffler 2008), although group sex ratios tend to be even or male biased (Lewis and van Schaik 2007). Finally, observations of females frequently mating with extragroup males at Beza (Brockman 1994; Richard 1992) may lend support for the decreased ability of Beza males to monopolize all females in their resident group.

Based on observations at Beza, Richard (1985) proposed that membership within a group is not necessary to mate with its females and that social group boundaries tend to break down in the mating season. In addition, females show positive mate choice toward resident and non-resident males (Brockman and Whitten 1996). Although lone males have occasionally been observed on the periphery of groups during the mating season at Kirindy, groups remain stable and females have only rarely been seen to mate with non-resident males (Mass, pers. obs.). This discrepancy is also reflected in the genetic paternity data. Thus, there appears to be some support for the use of different reproductive strategies by both males and females between the 2 sites. This may reflect differences in both group size and composition and environmental factors between Beza and Kirindy.

\section{Mate-Guarding as a Mechanism Underlying High Reproductive Skew}

Although alternative reproductive strategies such as sneak copulations can reduce the effectiveness of mate-guarding (Setchell et al. 2005), the genetic data suggest that they do not result in fertilization. The low frequency of both extragroup and intragroup subordinate male paternity (Kappeler and Schäffler 2008) imply that dominant males are able to monopolize almost all reproduction, and our results suggest that mateguarding is one important proximate aspect in this context. Monopolization of receptive females may in addition be facilitated by small female group size, as has been shown for langurs, wherein dominant males residing in multi-male groups also sire significantly more offspring than subordinates (Launhardt et al. 2001).

Our finding gives some insight into why, despite the small number of reproductively active females per group, some dominant males may not exclude potential rivals from group membership. Although there is a reproductive cost in having rival males present in a group as a small percentage of paternities are lost, the cost may not be high enough to risk fighting to evict them. Further, rival subordinate males may be tolerated by a dominant male if their presence benefits the group as a whole (Ostner and Kappeler 2004; van Hooff 2000). Although Lewis (2004) found that subordinate male sifakas provide services in terms of vigilance, grooming, and playing with infants, natal and non-natal subordinate males were not distinguished. However, if a dominant male is able to monopolize almost all paternities due to effective mate-guarding and if the presence of subordinate non-natal males benefits the group, this could help explain the observed tendency toward an even sex ratio in group composition. In addition, although non-natal subordinate males stay in the group with almost no reproductive success, this may be a better alternative to being a solitary male (Lewis and van Schaik 2007). 


\section{Conclusion}

Achieving the position of dominant male is ultimately the best reproductive tactic for a male Verreaux's sifaka. Although dominant males do not exclude potential rivals from group membership and subordinates have been observed to mate occasionally, dominant males are generally able to exclude rivals from successful reproduction. Results from this study show that mate-guarding is a viable dominant male reproductive tactic to monopolize receptive females. Mate-guarding is facilitated by both the temporal distribution of estrous females within a group and due to the ability of males to obtain information on female reproductive state via olfactory cues. Within the Kirindy population, the ability to exclude rivals from paternities suggests that dominant males are mate-guarding effectively. This ability, in turn, can explain the high reproductive skew observed within the population but not why non-natal subordinate males stay with little reproductive success. Information on mating skew and the possible benefits of the presence of non-natal males within a group are essential for understanding the tendency towards adult even sex ratio despite the small number of females in sifaka groups. In understanding the interplay of the reproductive strategies of both dominant males and subordinate non-natal males, we can start to comprehend the various lemur idiosyncrasies and the evolutionary forces that shaped them.

Acknowledgments We thank M. Daniel Rakotondravony and Mme. Olga Ramilijaona at the University of Antananarivo, the Comission Tripartite de Direction des Eaux et Forêts and the C.F.P.F. (now CNFEREF) Morondava for their authorization and support of this study. We thank Honoré Guy Rakotondrazanany for all his hard work in the forest and A. Heistermann and J. Hagedorn for their invaluable assistance with laboratory work. We thank M. Port and J. Barthold for valuable discussions on the manuscript, the Equipe Kirindy for all their support in the field, and 3 anonymous referees for constructive criticism of an earlier version of this manuscript. This research was supported by the DFG (KA 1082/9-1).

Open Access This article is distributed under the terms of the Creative Commons Attribution Noncommercial License which permits any noncommercial use, distribution, and reproduction in any medium, provided the original author(s) and source are credited.

\section{References}

Alberts, S. C., Altmann, J., \& Wilson, M. L. (1996). Mate guarding constrains foraging activity of male baboons. Animal Behaviour, 51, 1269-1277. doi:10.1006/anbe.1996.0131.

Altmann, J. (1974). Observational study of behavior-sampling methods. Behaviour, 49, $227-267$. doi:10.1163/156853974X00534.

Altmann, J. (1990). Primate males go where the females are. Animal Behaviour, 39, $193-195$. doi:10.1016/S0003-3472(05)80740-7.

Andersson, M. (1994). Sexual selection. Princeton, NJ: Princeton University Press.

Aujard, F., Heistermann, M., Thierry, B., \& Hodges, J. K. (1998). Functional significance of behavioral, morphological, and endocrine correlates across the ovarian cycle in semifree ranging female Tonkean macaques. American Journal of Primatology, 46, 285-309. doi:10.1002/(SICI)1098-2345(1998) 46:4<285::AID-AJP2>3.0.CO;2-8.

Bateman, A. J. (1948). Intra-sexual selection in Drosophila. Heredity, 2, 349-368. doi:10.1038/hdy.1948.21.

Benadi, G., Fichtel, C., \& Kappeler, P. M. (2008). Intergroup relations and home range use in Verreaux's sifaka (Propithecus verreauxi). American Journal of Primatology, 70, 1-10. doi: 10.1002/ajp.20588.

Bercovitch, F. B. (1983). Time budgets and consortships in olive baboons (Papio anubis). Folia Primatologica, 41, 180-190. doi:10.1159/000156130. 
Brauch, K., Pfefferle, D., Hodges, K., Fischer, J., \& Heistermann, M. (2007). Female sexual behavior and sexual swelling size as potential cues for males to discern the female fertile phase in free-ranging Barbary macaques (Macaca sylvanus) of Gibraltar. Hormones and Behavior, 52, 375-383. doi:10.1016/j.yhbeh.2007.06.001.

Brockman, D. K. (1994). Reproduction and mating systems of Verreaux's sifaka, Propithecus verreauxi, at Beza Mahafaly, Madagascar. Ph.D. thesis, Yale University, New Haven, CT.

Brockman, D. K. (1999). Reproductive behavior of female Propithecus verreauxi at Beza Mahafaly, Madagascar. International Journal of Primatology, 20, 375-398. doi:10.1023/A:1020500804442.

Brockman, D. K., \& Whitten, P. L. (1996). Reproduction in free-ranging Propithecus verreauxi: Estrus and the relationship between multiple partner matings and fertilization. American Journal of Physical Anthropology, 100, 57-69. doi:10.1002/(SICI)1096-8644(199605)100:1<57::AID-AJPA6>3.0.CO;2-A.

Cant, M. A., Otali, E., \& Mwanguhya, F. (2002). Fighting and mating between groups in a cooperatively breeding mammal, the banded mongoose. Ethology, 108, 541-555. doi:10.1046/j.14390310.2002.00795.x.

Carosi, M., Heistermann, M., \& Visalberghi, E. (1999). Display of preceptive behaviors in relation to urinary and fecal progestin levels over the ovarian cycle in female tufted capuchin monkeys. Hormones and Behavior, 36, 252-265. doi:10.1006/hbeh.1999.1545.

Cavigelli, S. A., \& Pereira, M. E. (2000). Mating season aggression and fecal testosterone levels in male ring-tailed lemurs (Lemur catta). Hormones and Behavior, 37, 246-255. doi:10.1006/ hbeh.2000.1585.

Clutton-Brock, T. H. (1989). Mammalian mating systems. Proceedings of the Royal Society of London. Series B. Biological Sciences, 236, 339-372.

Clutton-Brock, T. H., Harvey, P. H., \& Rudder, B. (1977). Sexual dimorphism, socionomic sex-ratio and body-weight in primates. Nature, 269, 797-800. doi:10.1038/269797a0.

Clutton-Brock, T. H., \& Vincent, A. C. J. (1991). Sexual selection and the potential reproductive rates of males and females. Nature, 351, 58-60. doi:10.1038/351058a0.

de Vries, H. (1998). Finding a dominance order most consistent with a linear hierarchy: A new procedure and review. Animal Behaviour, 55, 827-843. doi:10.1006/anbe.1997.0708.

Eberle, M., \& Kappeler, P. M. (2004). Sex in the dark: Determinants and consequences of mixed male mating tactics in Microcebus murinus, a small solitary nocturnal primate. Behavioral Ecology and Sociobiology, 57, 77-90. doi:10.1007/s00265-004-0826-1.

Emlen, S. T., \& Oring, L. W. (1977). Ecology, sexual selection, and evolution of mating systems. Science, 197, 215-223. doi:10.1126/science.327542.

Engelhardt, A., Heistermann, M., Hodges, J. K., Nurnberg, P., \& Niemitz, C. (2006). Determinants of male reproductive success in wild long-tailed macaques (Macaca fascicularis) - male monopolisation, female mate choice or post-copulatory mechanisms? Behavioral Ecology and Sociobiology, 59, 740752. doi:10.1007/s00265-005-0104-x.

Engelhardt, A., Hodges, J. K., Niemitz, C., \& Heistermann, M. (2004). Female sexual behaviour indicates the fertile phase in wild long-tailed macaques (Macaca fascicularis). Folia Primatologica, 75, 257258.

Engelhardt, A., Hodges, J. K., Niemitz, C., \& Heistermann, M. (2005). Female sexual behavior, but not sex skin swelling, reliably indicates the timing of the fertile phase in wild long-tailed macaques (Macaca fascicularis). Hormones and Behavior, 47, 195-204. doi:10.1016/j.yhbeh.2004.09.007.

Ferkin, M. H., Li, H. Z., \& Leonard, S. T. (2004). Meadow voles and prairie voles differ in the percentage of conspecific marks they over-mark. Acta Ethologica, 7, 1-7. doi:10.1007/s10211-004-0089-X.

Fichtel, C., Kraus, C., Ganswindt, A., \& Heistermann, M. (2007). Influence of reproductive season and rank on fecal glucocorticoid levels in free-ranging male Verreaux's sifakas (Propithecus verreauxi). Hormones and Behavior, 51, 640-648. doi:10.1016/j.yhbeh.2007.03.005.

Gachot-Neveu, H., Petit, M., \& Roeder, J. J. (1999). Paternity determination in two groups of Eulemur fulvus mayottensis: Implications for understanding mating strategies. International Journal of Primatology, 20, 107-119. doi:10.1023/A:1020588301716.

Gould, L., \& Ziegler, T. (2007). Variation in fecal testosterone levels, inter-male aggression, dominance rank and age during mating and post-mating periods in wild adult male ring-tailed lemurs (Lemur catta). American Journal of Primatology, 69, 1325-1339. doi:10.1002/ajp.20438.

Harrington, J. E. (1974). Olfactory communication in Lemur fulvus. In R. D. Martin, G. A. Doyle, \& A. Walker (Eds.), Prosimian biology (pp. 331-346). London: Duckworth.

Hayes, R. A., Morelli, T. L., \& Wright, P. C. (2004). Anogenital gland secretions of Lemur catta and Propithecus verreauxi coquereli: A preliminary chemical examination. American Journal of Primatology, 63, 49-62. doi:10.1002/ajp.20038. 
Hayes, R. A., Morelli, T. L., \& Wright, P. C. (2006). Volatile components of lemur scent secretions vary throughout the year. American Journal of Primatology, 68, 1202-1207. doi:10.1002/ajp.20319.

Heistermann, M., Tari, S., \& Hodges, J. K. (1993). Measurement of fecal steroids for monitoring ovarianfunction in new-world primates, Callitrichidae. Journal of Reproduction and Fertility, 99, 243-251. doi:10.1530/jrf.0.0990243.

Heistermann, M., Ziegler, T., van Schaik, C. P., Launhardt, K., Winkler, P., \& Hodges, J. K. (2001). Loss of oestrus, concealed ovulation and paternity confusion in free-ranging Hanuman langurs. Proceedings of the Royal Society of London. Series B. Biological Sciences, 268, 2445-2451. doi:10.1098/rspb.2001.1833.

Hill, D. A. (1987). Social relationship between adult male and female rhesus macaques. 1. Sexual consortships. Primates, 28, 439-456. doi:10.1007/BF02380860.

Hill, D. A. (1990). Social relationships between adult male and female rhesus macaques. 2. Nonsexual Affiliative Behavior. Primates, 31, 33-50. doi:10.1007/BF02381028.

Hinde, R. A. (1977). On assessing the bases of partner preferences. Behaviour, 62, 1-9. doi:10.1163/ 156853977 X00018.

Hinde, R. A., \& Atkinson, S. (1970). Assessing roles of social partners in maintaining mutual proximity, as exemplified by mother-infant relations in rhesus monkeys. Animal Behaviour, 18, 169-174. doi:10.1016/0003-3472(70)90087-4.

Huck, M. A., Lottker, P., \& Heymann, E. W. (2004). Proximate mechanisms of reproductive monopolization in male moustached tamarins (Saguinus mystax). American Journal of Primatology, 64, 39-56. doi:10.1002/ajp.20060.

Ims, R. A. (1988). Spatial clumping of sexually receptive females induces space sharing among male voles. Nature, 335, 541-543. doi:10.1038/335541a0.

Jolly, A. (1966). Lemur behavior. Chicago: University of Chicago Press.

Kappeler, P. M. (1990). The evolution of sexual size dimorphism in prosimian primates. American Journal of Primatology, 21, 201-214. doi:10.1002/ajp.1350210304.

Kappeler, P. M. (1991). Patterns of sexual dimorphism in body-weight among prosimian primates. Folia Primatologica, 57, 132-146. doi:10.1159/000156575.

Kappeler, P. M. (1998). To whom it may concern: The transmission and function of chemical signals in Lemur catta. Behavioral Ecology and Sociobiology, 42, 411-421. doi:10.1007/s002650050455.

Kappeler, P. M. (1999). Primate socioecology: New insights from males. Naturwissenschaften, 86, 18-29. doi:10.1007/s001140050563.

Kappeler, P. M., \& Schäffler, L. (2008). The lemur syndrome unresolved: Extreme male reproductive skew in sifakas (Propithecus verreauxi), a sexually monomorphic primate with female dominance. Behavioral Ecology and Sociobiology, 62, 1007-1010. doi:10.1007/s00265-007-0528-6.

Kraus, C., Heistermann, M., \& Kappeler, P. M. (1999). Physiological suppression of sexual function of subordinate males: A subtle form of intrasexual competition among male sifakas (Propithecus verreauxi)? Physiology \& Behavior, 66, 855-861. doi:10.1016/S0031-9384(99)00024-4.

Kubzdela, K. S. (1997). Sociodemography in diurnal primates: The effects of group size and female dominance rank on intra-group spatial distribution, feeding competition, female reproductive success, and female dispersal patterns in white sifaka, Propithecus verreauxi verreauxi. Ph.D. thesis, The University of Chicago, Chicago.

Kutsukake, N., \& Nunn, C. L. (2006). Comparative tests of reproductive skew in male primates: The roles of demographic factors and incomplete control. Behavioral Ecology and Sociobiology, 60, 695-706. doi:10.1007/s00265-006-0213-1.

Launhardt, K., Borries, C., Hardt, C., Epplen, J. T., \& Winkler, P. (2001). Paternity analysis of alternative male reproductive routes among the langurs (Semnopithecus entellus) of Ramnagar. Animal Behaviour, 61, 53-64. doi:10.1006/anbe.2000.1590.

Lawler, R. R. (2007). Fitness and extra-group reproduction in male Verreaux's sifaka: an analysis of reproductive success from 1989-1999. American Journal of Physical Anthropology, 132, 267-277. doi:10.1002/ajpa.20507.

Lawler, R. R., Richard, A. F., \& Riley, M. A. (2003). Genetic population structure of the white sifaka (Propithecus verreauxi verreauxi) at Beza Mahafaly Special Reserve, southwest Madagascar (19922001). Molecular Ecology, 12, 2307-2317. doi:10.1046/j.1365-294X.2003.01909.x.

Lawler, R. R., Richard, A. F., \& Riley, M. A. (2005). Intrasexual selection in Verreaux's sifaka (Propithecus verreauxi verreauxi). Journal of Human Evolution, 48, 259-277. doi:10.1016/j. jhevol.2004.11.005.

Lewis, R. J. (2004). Male-female relationships in sifaka (Propithecus verreauxi verreauxi): Power, conflict, and cooperation. Ph.D. dissertation, Durham, NC: Duke University. 
Lewis, R. J. (2005). Sex differences in scent-marking in sifaka: Mating conflict or male services. American Journal of Physical Anthropology, 128, 389-398. doi:10.1002/ajpa.20206.

Lewis, R. J. (2006). Scent marking in sifaka: No one function explains it all. American Journal of Primatology, 68, 622-636. doi:10.1002/ajp.20256.

Lewis, R. J., Razafindrasamba, S. M., \& Tolojanahary, J. P. (2003). Observed infanticide in a seasonal breeding prosimian (Propithecus verreauxi verreauxi) in Kirindy Forest, Madagascar. Folia Primatologica, 74, 101-103. doi:10.1159/000070006.

Lewis, R. J., \& van Schaik, C. P. (2007). Bimorphism in male Verreaux's sifaka in the Kirindy forest of Madagascar. International Journal of Primatology, 28, 159-182. doi:10.1007/s10764-006-9107-3.

Matsubara, M. (2003). Costs of mate guarding and opportunistic mating among wild male Japanese macaques. International Journal of Primatology, 24, 1057-1075. doi:10.1023/A:1026228312706.

Michael, R. P., \& Keverne, E. B. (1968). Pheromones in communication of sexual status in primates. Nature, 218, 746-749. doi:10.1038/218746a0.

Mitani, J. C., GrosLouis, J., \& Manson, J. H. (1996a). Number of males in primate groups: Comparative tests of competing hypotheses. American Journal of Primatology, 38, 315-332. doi:10.1002/(SICI) 1098-2345(1996)38:4<315::AID-AJP3>3.0.CO;2-1.

Mitani, J. C., GrosLouis, J., \& Richards, A. F. (1996b). Sexual dimorphism, the operational sex ratio, and the intensity of male competition in polygynous primates. American Naturalist, 147, 966-980. doi:10.1086/285888.

Nunn, C. L. (1999). The number of males in primate social groups: A comparative test of the socioecological model. Behavioral Ecology and Sociobiology, 46, 1-13. doi:10.1007/s002650050586.

Ostner, J., \& Kappeler, P. M. (2004). Male life history and the unusual adult sex ratios of redfronted lemur, Eulemur fulvus rufus, groups. Animal Behaviour, 67, 249-259. doi:10.1016/j.anbehav.2003.05.012.

Ostner, J., Kappeler, P. M., \& Heistermann, M. (2002). Seasonal variation and social correlates of androgen excretion in male redfronted lemurs (Eulemur fulvus rufus). Behavioral Ecology and Sociobiology, 52, 485-495. doi:10.1007/s00265-002-0532-9.

Palagi, E., Telara, S., \& Borgognini Tarli, S. M. (2004). Reproductive strategies in Lemur catta: balance among sending, recieving and countermarking scent signals. International Journal of Primatology, 25, 1019-1031. doi:10.1023/B:IJOP.0000043349.23082.c0.

Parga, J. A. (2003). Copulatory plug displacement evidences sperm competition in Lemur catta. International Journal of Primatology, 24, 889-899. doi:10.1023/A:1024637024088.

Pereira, M. E., \& Kappeler, P. M. (1997). Divergent systems of agonistic behavior in lemurid primates. Behavior, 134, 225-274.

Plavcan, J. M. (1999). Mating systems, intrasexual competition and sexual dimorphism in primates. In P. C. Lee (Ed.), Comparative primate socioecology (pp. 241-269). Cambridge, UK: Cambridge University Press.

Plavcan, J. M. (2001). Sexual dimorphism in primate evolution. Yearbook of Physical Anthropology, 44, 25-53. doi:10.1002/ajpa.10011.

Plavcan, J. M., \& van Schaik, C. P. (1997). Intrasexual competition and body weight dimorphism in anthropoid primates. American Journal of Physical Anthropology, 103, 37-67. doi:10.1002/(SICI) 1096-8644(199705)103:1<37::AID-AJPA4>3.0.CO;2-A.

Pochron, S. T., Morelli, T. L., Scirbona, J., \& Wright, P. C. (2005). Sex differences in scent marking in Propithecus edwardsi of Ranomafana National Park, Madagascar. American Journal of Primatology, 66, 97-110. doi:10.1002/ajp.20130.

Richard, A. F. (1974a). Intraspecific variation in social-organization and ecology of Propithecus verreauxi. Folia Primatologica, 22, 178-207. doi:10.1159/000155624.

Richard, A. F., Rakotomanga, P., \& Schwartz, M. (1993). Dispersal by Propithecus verreauxi at Beza Mahafaly, Madagascar: 1984-1991. American Journal of Primatology, 30, 1-20. doi:10.1002/ ajp.1350300102.

Richard, A. F. (1974b). Patterns of mating in Propithecus verreauxi. In R. D. Martin, G. A. Doyle, \& A. C. Walker (Eds.), Prosimian behaviour (pp. 49-74). London: Duckworth.

Richard, A. F. (1985). Social boundaries in a Malagasy prosimian, the sifaka (Propithecus verreauxi). International Journal of Primatology, 6, 553-568. doi:10.1007/BF02692288.

Richard, A. F. (1987). Malagasy prosimians: Female dominance. In B. B. Smuts, D. L. Cheney, R. M. Seyfarth, R. W. Wrangham, \& T. T. Struhsaker (Eds.), Primate societies (pp. 25-33). Chicago: University of Chicago Press.

Richard, A. F. (1992). Aggressive competition between males, female-controlled polygyny and sexual monomorphism in a malagasy primate, Propithecus verreauxi. Journal of Human Evolution, 22, 395406. doi:10.1016/0047-2484(92)90067-J. 
Richard, A. F., Dewar, R. E., Schwartz, M., \& Ratsirarson, J. (2002). Life in the slow lane? Demography and life histories of male and female sifaka (Propithecus verreauxi verreauxi). Journal of Zoology, 256, 421-436.

Richard, A. F., Rakotomanga, P., \& Schwartz, M. (1991). Demography of Propithecus verreauxi at Beza Mahafaly, Madagascar: Sex ratio, survival and fertility, 1984-1988. American Journal of Physical Anthropology, 84, 307-322. doi:10.1002/ajpa.1330840307.

Rümenap, S. (1997). Ethno-Endokrinologie freilebender weiblicher Kronensifakas (Propithecus verreauxi verreauxi, Grandidier 1867) in der Paarungszeit, unter besonderer Berücksichtigung altersspezifischer Unterschiede. Göttingen: Universität Göttingen.

Sauther, M. L. (1991). Reproductive-behavior of free-ranging Lemur Catta at Beza Mahafaly Special Reserve, Madagascar. American Journal of Physical Anthropology, 84, 463-477. doi:10.1002/ ajpa.1330840409.

Say, L., Pontier, D., \& Natoli, E. (2001). Influence of oestrus synchronization on male reprodcuctive success in the domestic cat (Felis catus L.). Proceedings of the Royal Society of London. Series B. Biological Sciences, 268, 1049-1053. doi:10.1098/rspb.2001.1583.

Schilling, A. (1979). Olfactory communication in prosimians. In G. A. Doyle, \& R. D. Martin (Eds.), The study of prosimian behavior (pp. 461-542). New York: Academic Press.

Semple, S. (1998). The function of barbary macaque copulation calls. Proceedings of the Royal Society of London. Series B. Biological Sciences, 265, 287-291. doi:10.1098/rspb.1998.0294.

Setchell, J. M., Charpentier, M., \& Wickings, E. J. (2005). Mate guarding and paternity in mandrills: Factors influencing alpha male monopoly. Animal Behaviour, 70, 1105-1120. doi:10.1016/j. anbehav.2005.02.021.

Setchell, J. M., \& Wickings, E. J. (2004). Sexual swelling in mandrills (Mandrillus sphinx): A test of the reliable indicator hypothesis. Behavioral Ecology, 15, 438-445. doi:10.1093/beheco/arh027.

Shideler, S. E., Ortuno, A. M., Moran, F. M., Moorman, E. A., \& Lasley, B. L. (1993). Simple extraction and enzyme immunoassays for estrogen and progesterone metabolites in the feces of Macaca fascicularis during non-conceptive and conceptive ovarian cycles. Biology of Reproduction, 48, 1290-1298. doi:10.1095/biolreprod48.6.1290.

Sorg, J., Ganzhorn, J. U., \& Kappeler, P. M. (2003). Forestry and research in the Kirindy Forest/Centre de Formation Professionnelle Forestière. In S. Goodman, \& J. Benstead (Eds.), The natural history of Madagascar (pp. 1512-1519). Chicago: University of Chicago Press.

Trivers, R. L. (1972). Parental investment and sexual selection. In B. Campbell (Ed.), Sexual selection and the descent of man (pp. 136-179). Chicago: Aldine.

Tutin, C. E. G. (1979). Mating Patterns and reproductive strategies in a community of wild chimpanzees (Pan troglodytes schweinfurthii). Behavioral Ecology and Sociobiology, 6, 29-38. doi:10.1007/ BF00293242.

van Hooff, J. A. R. A. M. (2000). Relationships among non-human primate males: A deductive framework. In P. M. Kappeler (Ed.), Primate males: Causes and consequences of variation in group composition (pp. 183-191). Cambridge, UK: Cambridge University Press.

van Schaik, C. P., \& Janson, C. H. (2000). Infanticide by males and its implications. Cambridge, UK: Cambridge University Press.

van Schaik, C. P., Pradhan, G. R., \& van Noordwijk, M. A. (2004). Mating conflict in primates: Infanticide, sexual harassment and female sexuality. In P. M. Kappeler, \& C. P. van Schaik (Eds.), Sexual selection in primates: New and comparive perspectives (pp. 131-150). Cambridge, UK: Cambridge University Press.

Wasser, S. K., Risler, L., \& Steiner, R. A. (1988). Excreted steroids in primate feces over the menstrualcycle and pregnancy. Biology of Reproduction, 39, 862-872. doi:10.1095/biolreprod39.4.862.

Wolovich, C. K., \& Evans, S. (2007). Sociosexual behavior and chemical communication of Aotus nancymaae. International Journal of Primatology, 28, 1299-1313. doi:10.1007/s10764-007-9228-3.

Zehr, J. L., Tannenbaum, P. L., Jones, B., \& Wallen, K. (2000). Peak occurrence of female sexual initiation predicts day of conception in rhesus monkeys (Macaca mulatta). Reproduction, Fertility, and Development, 12, 397-404. doi:10.1071/RD00080.

Ziegler, T., Hodges, K., Winkler, P., \& Heistermann, M. (2000). Hormonal correlates of reproductive seasonality in wild female Hanuman langurs (Presbytis entellus). American Journal of Primatology, 51, 119-134. doi:10.1002/(SICI)1098-2345(200006)51:2<119::AID-AJP2>3.0.CO;2-O. 